\title{
The Characterization of Soluble Amyloid Prepared in Water
}

\author{
M. Pras, M. Schubert, D. Zuckerr-Franklin, A. Rimon, and E. C. Franklin \\ From the Department of Medicine, Rheumatic Diseases Study Group, New \\ York University School of Medicine, New York 10016
}

A B S T RACT Amyloid was extracted from the spleen of a patient with primary amyloidosis by homogenizing it at high speed with water after preliminary treatments, first to remove proteins soluble in saline, and then to remove salts. The extracts containing amyloid appeared to be clear at concentrations up to $6 \mathrm{mg} / \mathrm{ml}$ of protein. The material gave little sediment on being centrifuged up to $20,000 \mathrm{~g}$ for $1 \mathrm{hr}$, but the protein was sedimented at $100,000 \mathrm{~g}$ in $1 \mathrm{hr}$. The amyloid could be precipitated from the extracts by addition of $\mathrm{NaCl}$ to $0.0075 \mathrm{~mole} /$ liter or of $\mathrm{CaCl}_{2}$ to 0.0025 mole/liter. The protein-bound Congo red formed a red precipitate and this property was used to estimate recovery and purity of amyloid during extraction.

On electronmicroscopy the isolated amyloid proved to be morphologically pure. It existed either as single filaments measuring $60-80 \AA$ in diameter or as large aggregates of these filaments.

Freshly isolated amyloid in water sedimented as a single homogeneous peak with an $s^{\circ}{ }_{20, w}$ of about 45-50S. On standing, the solution became cloudy and more rapidly sedimenting components appeared. On electrophoresis the material migrated as a homogeneous peak towards the anode. The protein had an amino acid composition different from that of all known serum proteins. It was rich in acidic amino acids and had little cysteine and methionine and no hydroxyproline. The total content of carbohydrate was less than $2 \%$.

Dr. Pras' permanent address is Tel Hashomer Hospital, Tel Aviv, Israel.

Dr. Rimon's permanent address is Tel-Aviv University, Tel Aviv, Israel.

Received for publication 29 July 1967 and in revised form 25 November 1967.

\section{INTRODUCTION}

Investigations on amyloid have been hampered by the fact that no solvent has been found in which this material can be quantitatively extracted and obtained in a reasonably pure and stable state.

Amyloid fibrils are known to be highly insoluble in neutral aqueous media of ionic strengths commonly used $(1,2)$. In recent years amyloid has been dissolved in dilute alkali (3) and in concentrated urea solutions $(4,5)$. However, the yields by these procedures are relatively poor, and the extracted amyloid is only partially brought into solution. During the isolation procedures some of the material was degraded to particles of lower molecular weight and some of it could not be fully reconstituted to its original fibrillar form.

Reports on the composition of amyloid by different investigators have shown wide variation in the contents of carbohydrate components $(6-8)$ and amino acids $(6,9,10)$. This variability can probably be attributed to the difficulties of purifying a substance that cannot be dissolved without decomposition. Cohen and Calkins (11) demonstrated the fibrillar character of several types of amyloid. Since these fibrils have all the tinctorial characteristics of amyloid, it seems likely that they are amyloid, while the interfibrillar material is an impurity. The demonstration of fibrils as the main constituent in amyloid has resulted in a number of electronmicroscope studies $(5,12-18)$. In general the amyloid fibrils appear to be 70-100 A wide and of lengths that range from 400 to $16,000 \mathrm{~A}$. A detailed discussion of the structure of these fibrils has recently been published by Shirahama and Cohen (18).

In an effort to obtain a solution of amyloid in a stable form, a method has been developed by which 
a major fraction of amyloid was extracted from the spleen of a patient with primary amyloidosis in distilled water. In the course of this procedure, it was possible to obtain a clear solution, containing amyloid in distilled water that lent itself readily to physicochemical, chemical, and ultrastructural characterization.

\section{METHODS}

Tissue. The tissue used for extraction was a specimen of human spleen obtained postmortem from a patient with primary amyloidosis. The spleen was stored at $-20^{\circ} \mathrm{C}$ until thawed and subjected to the procedures outlined below. Histological examination showed classical amyloidosis; the hematoxylin-eosin stain showed an accumulation of extracellular eosinophilic material. The material stained red with Congo red and showed green birefringence with a polarizing microscope (19). Crystal violet stained it metrachromatically. Electronmicroscope examination of the "top layer," prepared by the method of Cohen and Calkins (20), using negative staining technique, demonstrated fine fibrils of $100 \mathrm{~A} \pm 20$ in diameter as well as collagen bundles.

Separation and purification. All procedures were carried out at $4^{\circ} \mathrm{C}$. The Virtis -45 high speed homogenizer was used for all homogenizations. A Spinco model L centrifuge with a No. 30 rotor was used for all centrifugation.

The initial steps do not differ basically from the original method of Cohen and Calkins (20). $20 \mathrm{~g}$ of the amyloidladen spleen and $400 \mathrm{ml}$ of $0.15 \mathrm{M} \mathrm{NaCl}$ were homogenized in a Virtis-45 high speed homogenizer for $5 \mathrm{~min}$, and the mixture was centrifuged at $10,000 \mathrm{rpm}$ for $30 \mathrm{~min}$. The supernatant solution was discarded. The sediment was homogenized as before with $400 \mathrm{ml}$ of $0.15 \mathrm{M} \mathrm{NaCl}$, and the mixture centrifuged as before. These operations were repeated six or seven times. The last supernatant solution had an absorbance of less than 0.075 at $280 \mathrm{~m} \mu$.

At this point most soluble proteins and other soluble materials of the spleen had been removed. Salt was now removed from the residue by homogenizing the residue with $300 \mathrm{ml}$ of distilled water and centrifuging the suspension at 30,000 rpm for $1 \mathrm{hr}$. The supernatant (supernatant I) contained only small quantities of protein $(0.1$ $\mathrm{mg} / \mathrm{ml}$ ) and was discarded. The residue was homogenized with $200 \mathrm{ml}$ of distilled water and centrifuged at $30,000 \mathrm{rpm}$ for an hour. This yielded a supernatant (supernatant II) which contained a large quantity of protein, about $2 \mathrm{mg} / \mathrm{ml}$. The residue was homogenized with $200 \mathrm{ml}$ of distilled water, and after centrifugation at 30,$000 \mathrm{rpm}$ for $1 \mathrm{hr}$, the supernatant (supernatant III) again contained about $2 \mathrm{mg}$ of protein per $\mathrm{ml}$. The fourth and last homogenization was done with $70 \mathrm{ml}$ of distilled water and the mixture was centrifuged at $10,000 \mathrm{rpm}$ for $3 \mathrm{hr}$. The supernatant (Supernatant IV) had a protein content of about $4 \mathrm{mg} / \mathrm{ml}$. Supernatants II, III, and IV were kept in the cold at $4^{\circ} \mathrm{C}$, and all showed similar properties. The total yield of the soluble amyloid from $3.2 \mathrm{~g}$ of dry tissue was $1100 \mathrm{mg}$. Thus, about $34 \%$ of the dry weight of the tissue was amyloid. Normal spleen, extracted by the same procedure, did not contain measurable amounts of protein in supernatants II, III, and IV.

Quantitative Congo red test. Congo red is bound by amyloid to form a stable product. Although this staining property and its characteristic birefringence in the polarization microscope have been used as a valuable qualitative identification method, the interaction between Congo red and amyloid has not been studied quantitatively. Therefore, to compare quantitatively the relative purities of different amyloid preparations, we developed the procedure described below. The test depends on the fact that suspensions of amyloid in saline bind a fixed amount of Congo red and that the stained insoluble amyloid is easily removed by centrifugation at low speeds.

The stock Congo red solution contains $1 \mathrm{~g}$ in $100 \mathrm{ml}$ of distilled water. For use, a working solution is made by diluting $1 \mathrm{ml}$ of the stock solution with $0.15 \mathrm{M} \mathrm{NaCl}$ to $100 \mathrm{ml}$. Generally, $2 \mathrm{ml}$ of an unknown solution, containing no more than $2 \mathrm{mg}$ of amyloid, is added to $10 \mathrm{ml}$ of the Congo red working solution. As a control, $10 \mathrm{ml}$ of Congo red is diluted with $2 \mathrm{ml}$ of water. After incubating an hour, the mixture of dye and sample is centrifuged in a table top centrifuge (International Clinical Centrifuge, International Equipment Co., Needham Heights, Mass.), and the absorbance of the supernatant solution is measured at $490 \mathrm{~m} \mu$. The amount of Congo red bound to and removed by the amyloid in the sample is calculated by comparing the amount of Congo red left in solution in the sample and the control. Fig. 1 shows how the absorbance of the supernatant solution decreases after addition of increasing amounts of amyloid. The amyloid used to prepare the curve in Fig. 1 was a solution in water similar to that called supernatant II. In contrast, solutions of serum proteins or suspensions of collagen removed little if any Congo red from solution. The test has, therefore, been used as an assay procedure to estimate the amount of amyloid in the solution of amyloid in water (supernatants II, III, and IV), and to estimate the total amount recovered. Because of the presence of hemoglobin which interferes with the colorimetric reading and elastin and collagen which bind Congo red

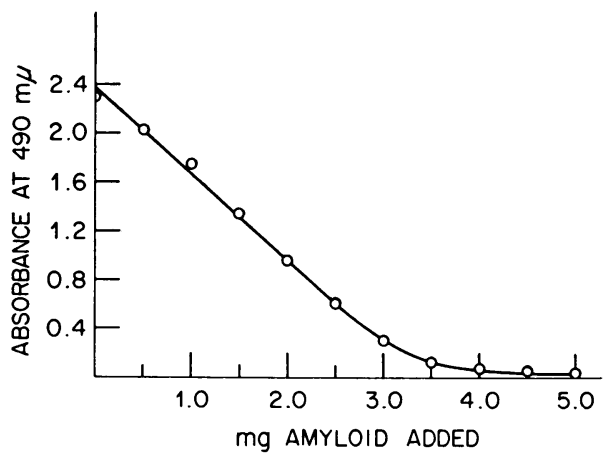

FIGURE 1 The linear relation between the amount of Congo red left in solution, measured by the absorbance at $490 \mathrm{~m} \mu$, and the amount of amyloid added. 
in tissue and in the insoluble residues, the quantitative Congo red binding could not be used to provide a precise estimate of the amount of amyloid in the tissue or the fraction of the total which was recovered. However, it appears likely that the bulk of the amyloid was extracted from the spleen, since the final product constituted about $34 \%$ of the dry weight of the spleen.

Physical and chemical studies. The sedimentation properties of the supernatants of different preparations were studied in the Spinco model $\mathrm{E}$ analytical ultracentrifuge at $20^{\circ} \mathrm{C}$ and at speeds ranging from 20,400 to $52,640 \mathrm{rpm}$. Because of the solubility properties of the material all studies were done in distilled water. Protein concentrations of the samples ranged from 1 to 4 $\mathrm{mg} / \mathrm{ml}$. Sedimentataion coefficients were calculated as described by Trautman (21), and the sedimentation coefficient at infinite dilution was determined by extrapolation from four values obtained at different concentrations.

Electrophoresis was carried out in a Perkin-Elmer apparatus, model 38A (22). Optical absorption spectra were recorded with a Beckman model DU spectrophotometer. The nitrogen content was determined by microKjeldahl procedure. Amino acid content was determined by the automatic amino acid analyzer (Spinco model 120) (23). Hydroxylproline was determined by the Woessner method (24). Neutral sugars were determined by the anthrone method (25), hexosamines by the Elson and Morgan method (26), uronic acid by Dische's carbazol method (27), and sialic acid by Warren's method (28).

Electron microscopy. To characterize the structure of the isolated amyloid we subjected two preparations to electron microscopy: (a) amyloid suspended in distilled water referred to as soluble amyloid, and $(b)$ amyloid suspended in $0.15 \mathrm{M}$ saline. In saline, purified amyloid formed a precipitate that was suitable for embedding according to standard methods used in electron microscopy as well as for direct examination with the aid of the negative staining technique (29). The precipitate was fixed with $3 \%$ glutaraldehyde (30) and (or) $2 \%$ osmium tetroxide, dehydrated in increasing concentrations of alcohol and propylene oxide, and embedded in Epon 812 (31). Thin sections were cut with an LKB ultrotome, stained with uranyl acetate (32) and (or) lead hydroxide (33), and viewed with a Siemens Elmiskop I electron microscope at instrument magnifications of $15,000-60,000$. Negative staining was carried out either by allowing a drop of the suspension to dry on a grid and subsequently contrasting it with $1 \%$ phosphotungstic acid (PTA) at $\mathrm{pH} 5-5.5$ or by suspending the amyloid in an equal volume of $2 \% \mathrm{PTA}$ or $0.5 \%$ uranyl oxalate (34) and subsequently applying the mixture to a carbon-coated Formvar-covered grid. Soluble amyloid was fixed with an equal amount of unbuffered $6 \%$ glutaraldehyde in distilled $\mathrm{H}_{2} \mathrm{O}$. The protein precipitated upon addition of the fixative and could thus be embedded in the same manner as the amyloid in saline. For negative staining a drop of amyloid in solution was allowed to dry on the grid after which it was contrasted with $1 \%$ PTA or uranyl oxalate.

\section{RESULTS}

General appearance. Supernatants II, III, and IV had a straw color and a clear serous appearance. They contained 2.1, 1.7, and $3.6 \mathrm{mg}$ of protein per $\mathrm{ml}$, respectively, checked by biuret and Folin methods. The protein could be sedimented completely at $100,000 \mathrm{~g}$ in $1 \mathrm{hr}$ in the form of a brown gel. After storage at $4{ }^{\circ} \mathrm{C}$ for a week or more, an opalescence gradually appeared and much of the material could now be sedimented at $20,000 \mathrm{~g}$. At room temperature the opalescence appeared within 2 days. When small quantities of different salts were added $\left(\mathrm{NaCl}, \mathrm{CaCl}_{2}\right.$, or even glycine buffer at various alkaline $\mathrm{pH}$ 's) the clear solution became opalescent within minutes and a precipitate was formed within $1 \mathrm{hr}$.

Solubility and Congo red binding. To check the effect of salt on the solubility of this protein, we mixed $2 \mathrm{ml}$ of supernatants II, III, or IV containing $2 \mathrm{mg}$ of protein with an equal volume of solutions containing $\mathrm{NaCl}$ or $\mathrm{CaCl}_{2}$ at concentrations ranging from 0.005 to 0.3 mole/liter. After an incubation period of $3 \mathrm{hr}$, the mixtures were sedimented at $500 \mathrm{~g}$ for $3 \mathrm{~min}$ and the supernatants were then checked for protein content by measuring the absorbance at $280 \mathrm{~m} \mu$. The diagram in Fig. 2 shows that the protein precipitates in the presence of $\mathrm{NaCl}$ at concentrations as low as 0.0075

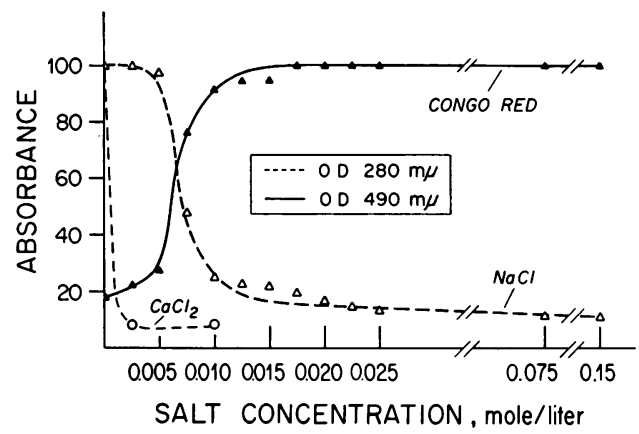

Figure 2 Relation between the amount of amyloid left in solution and the concentration of added salt, $\mathrm{NaCl}$ or $\mathrm{CaCl}_{2}$. The amount of amyloid left in solution was determined in two ways: (a) by the per cent of the initial absorbance at $280 \mathrm{~m} \mu$ left in the supernatant solution after adding salt and removing precipitated amyloid by centrifugation, and $(b)$ by measuring the per cent of Congo red in saline not precipitated when added to the same supernatant solution. The solid Congo red line was obtained with the supernatant solutions after the addition of $\mathrm{NaCl}$. 
$0.01 \mathrm{~mole} /$ liter and in solutions of $\mathrm{CaCl}_{2}$ at concentrations as low as 0.0025 mole/liter, and that precipitation was virtually complete in either solution at concentrations of salt greater than 0.01 mole/liter.

Addition of Congo red in $0.15 \mathrm{M} \mathrm{NaCl}$ to supernatants II, III, and IV resulted in a red gelatinous precipitate within $1 \mathrm{hr}$. This precipitate showed the typical green birefringence of amyloid in the polarizing microscope (6). As shown in Fig. 1, the amount of Congo red bound was proportional to the amount of protein added. Studies with several preparations which appeared to be pure electron microscopically and sedimented as a single peak in the ultracentrifuge showed that $1 \mathrm{mg}$ of protein bound $0.32 \mathrm{mg}$ of Congo red (Table I).

Another method of measuring the amount of amyloid left in solution after the addition of salt (Fig. 2) was to add an equal amount of a Congo red solution in $0.15 \mathrm{M} \mathrm{NaCl}$ to each of the supernatant solutions, incubate the mixture for $1 \mathrm{hr}$, centrifuge it again at $500 \mathrm{~g}$ for $30 \mathrm{~min}$, and read the optical density of the supernatants at $490 \mathrm{~m} \mu$. The solid line in Fig. 2 is the mirror image of the dashed line obtained with $\mathrm{NaCl}$ and clearly shows that Congo red binding can be used as an alternate method for quantitating amyloid in solution.

Chemical analysis. The nitrogen content of the protein in supernatant II was $14.3 \%$. Comparable values were obtained by Cohen (6) on purified amyloid fibrils and by Benditt, Lagunoff, Eriksen,

TABLE I

Relationship of the Amount of Congo Red Bound per Milligram of Protein at Various Stages of the Purification of A myloid

\begin{tabular}{|c|c|c|c|}
\hline & $\begin{array}{l}\text { mg pro- } \\
\text { tein } / \mathrm{ml}\end{array}$ & $\begin{array}{l}\mathrm{mg} \text { Congo red } \\
\mathrm{removed} / \mathrm{ml}\end{array}$ & $\begin{array}{l}\mathrm{mg} \text { Congo } \\
\mathrm{red} / \mathrm{mg} \\
\text { protein }\end{array}$ \\
\hline $\begin{array}{l}\text { Spleen homogenate, } \\
20 \mathrm{~g} \text { spleen in } \\
400 \mathrm{ml} \text { normal } \\
\text { saline }\end{array}$ & 8.01 & 0.87 & 0.11 \\
\hline $\begin{array}{l}\text { Residue left, after } \\
7 \text { washings in } \\
\text { saline, } 400 \mathrm{ml}\end{array}$ & 3.4 & 0.82 & 0.24 \\
\hline $\begin{array}{l}\text { Amyloid solution in } \\
\mathrm{H}_{2} \mathrm{O} \text { (supernatants } \\
\text { II, III, IV) }\end{array}$ & 2.7 & 0.88 & 0.32 \\
\hline
\end{tabular}

TABLE II

Amino Acid Composition of Soluble Amyloid

\begin{tabular}{lc} 
& umoles $/ 100 \mathrm{mg}$ \\
Lysine & 43.0 \\
Histidine & 14.9 \\
Ammonia & 92.6 \\
Arginine & 28.4 \\
Aspartic acid & 63.4 \\
Threonine & 52.6 \\
Serine & 78.3 \\
Glutamic acid & 84.0 \\
Proline & 54.5 \\
Glycine & 78.0 \\
Alanine & 71.2 \\
Cystine (half) & 9.5 \\
Valine & 61.7 \\
Methionine & 6.0 \\
Isoleucine & 27.1 \\
Leucine & 58.9 \\
Tyrosine & 28.4 \\
Phenylalanine & 26.0 \\
Hydroxyproline & 0 \\
\hline
\end{tabular}

* Determined separately (24).

and Iseri (4) on urea separated amyloid and by Pirani, Bestetti, Catchpole, and Meskauskas (35).

The amino acid composition, expressed as micromoles per $100 \mathrm{mg}$ of protein, is listed in Table II. There is a predominance of acidic amino acids, a low content of cysteine and methionine, and no hydroxyproline. These results are similar to those found by Cohen (6) and Benditt and Eriksen (5).

The values of total hexoses, hexosamines, uronic acid, and sialic acid expressed as per cent of dry weight are listed in Table III. The total carbohydrate was less than $2.0 \%$, and the amounts in each of the three fractions studied were rather constant.

The ultraviolet spectral absorptions of the three supernatants and of different preparations were similar, each having an absorption peak at $280 \mathrm{~m} \mu$ and a small depression at $255 \mathrm{~m} \mu$ (see Fig. 3).

TABLE III

Carbohydrate Composition of Soluble Amyloid

\begin{tabular}{lcccc}
\hline & $\begin{array}{c}\text { Neutral } \\
\text { sugars }\end{array}$ & $\begin{array}{c}\text { Hexosa- } \\
\text { mines }\end{array}$ & $\begin{array}{c}\text { Uronic } \\
\text { acid }\end{array}$ & $\begin{array}{c}\text { Sialic } \\
\text { acid }\end{array}$ \\
\hline & & \multicolumn{4}{c}{ \% of dry } & weight \\
Supernatant II & 1.17 & 0.26 & 0.23 & 0.12 \\
Supernatant III & 1.31 & 0.18 & 0.30 & 0.10 \\
Supernatant IV & 1.34 & 0.25 & 0.27 & 0.13 \\
\hline
\end{tabular}




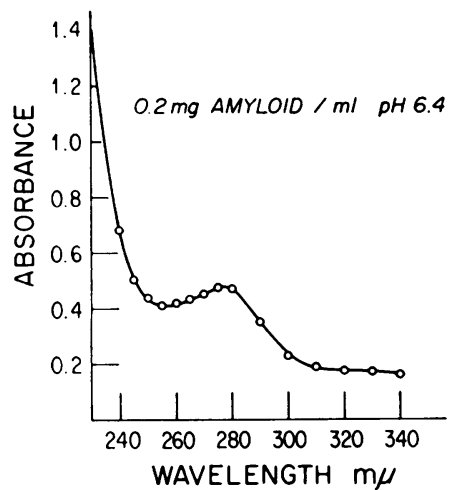

FigURE 3 Ultraviolet absorption spectrum of amyloid in water.

Electrophoresis. In free electrophoresis in 0.1 м unbuffered Tris, $\mathrm{pH} 10$, supernatant IV migrated as a single sharp peak towards the anode. An accurate mobility could not be calculated since the low conductivity of the Tris solution did not allow for more than $0.1 \mathrm{ma}$ of current to be used. In this medium amyloid does not precipitate, whereas in salt solutions it does.

Sedimentation studies. Because of the solubility properties, all studies were done in distilled water. Freshly prepared solutions of supernatants II, III, or IV sedimented as a single, rather homogeneous peak in the analytical ultracentrifuge at speeds ranging from 20,000-52,000 rpm (Fig. $4 a$ ). Occasionally, a small shoulder or a trace of more rapidly sedimenting components was noted. The concentration estimated from the area under the peak corresponded very closely to the initial protein concentration and indicated that more than $95 \%$ of the material present was found in the major peak. The sedimentation coefficient at infinite dilution for several preparations was calculated to be 45-50S (Fig. 5). More prolonged homogenization, as in supernatants III and IV, or treatment with ultrasound $(80,000$ cycles $/ \mathrm{sec}, 15$ min) or with $6 \mathrm{~m}$ urea solution did not significantly change the sedimentation coefficient of the protein.

Storage of the material at $4^{\circ} \mathrm{C}$ for a week caused it to become opalescent. When the aged preparations were examined in the ultracentrifuge, they were usually composed of two peaks (Fig. $4 b$ ) ; the slow peak had the same sedimentation coefficient as the fresh material, while the rapid peak had a sedimentation coefficient of about $75 \mathrm{~S}$. This

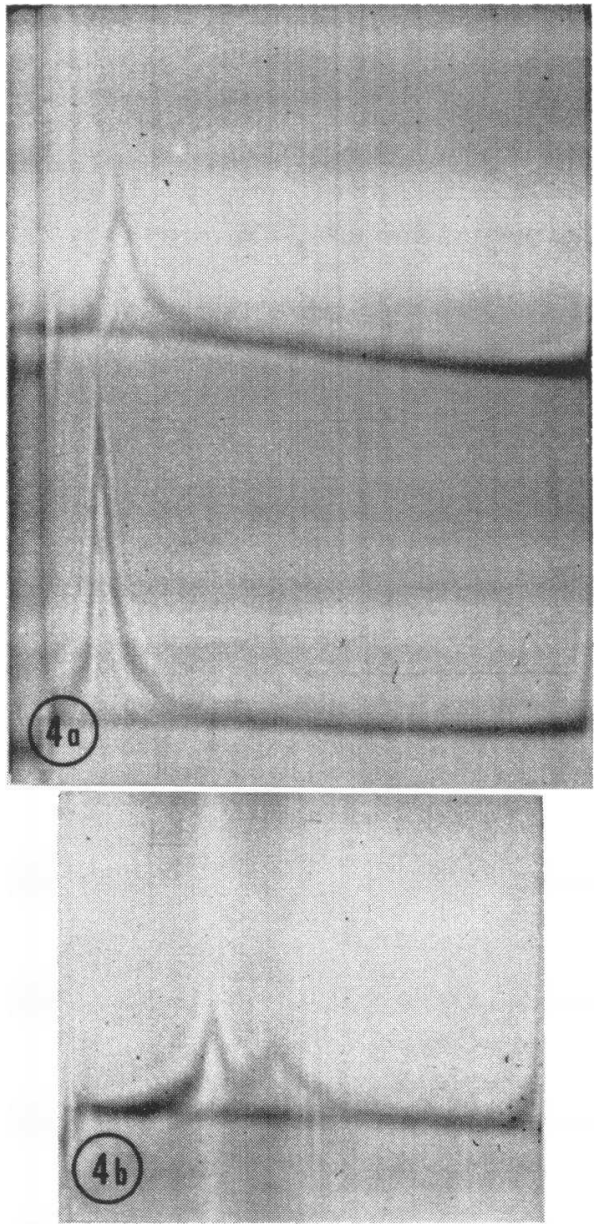

FIGURE $4 a$, Ultracentrifugal patterns of purified amyloid in distilled water. Bottom $3 \mathrm{mg} / \mathrm{ml}$; top $2 \mathrm{mg} / \mathrm{ml}$. Photograph after $24 \mathrm{~min}$ at 20,400 rpm. Phase plate angle $-45^{\circ} . b$, Ultracentrifugal patterns of "aged" amyloid in distilled water. There are two components with sedimentation coefficients of $50 \mathrm{~S}$ and 71S. Photograph taken after $36 \mathrm{~min}$ at $20,400 \mathrm{rpm}$. Phase plate angle $-45^{\circ}$.

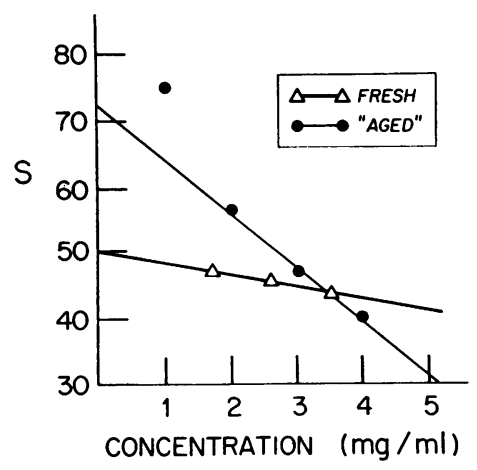

FIGURE 5 Sedimentation coefficient of purified amyloid in distilled water plotted against protein concentration. $s^{\circ}{ }_{20, w}$ ranged between 45 and $50 \mathrm{~S}$. 


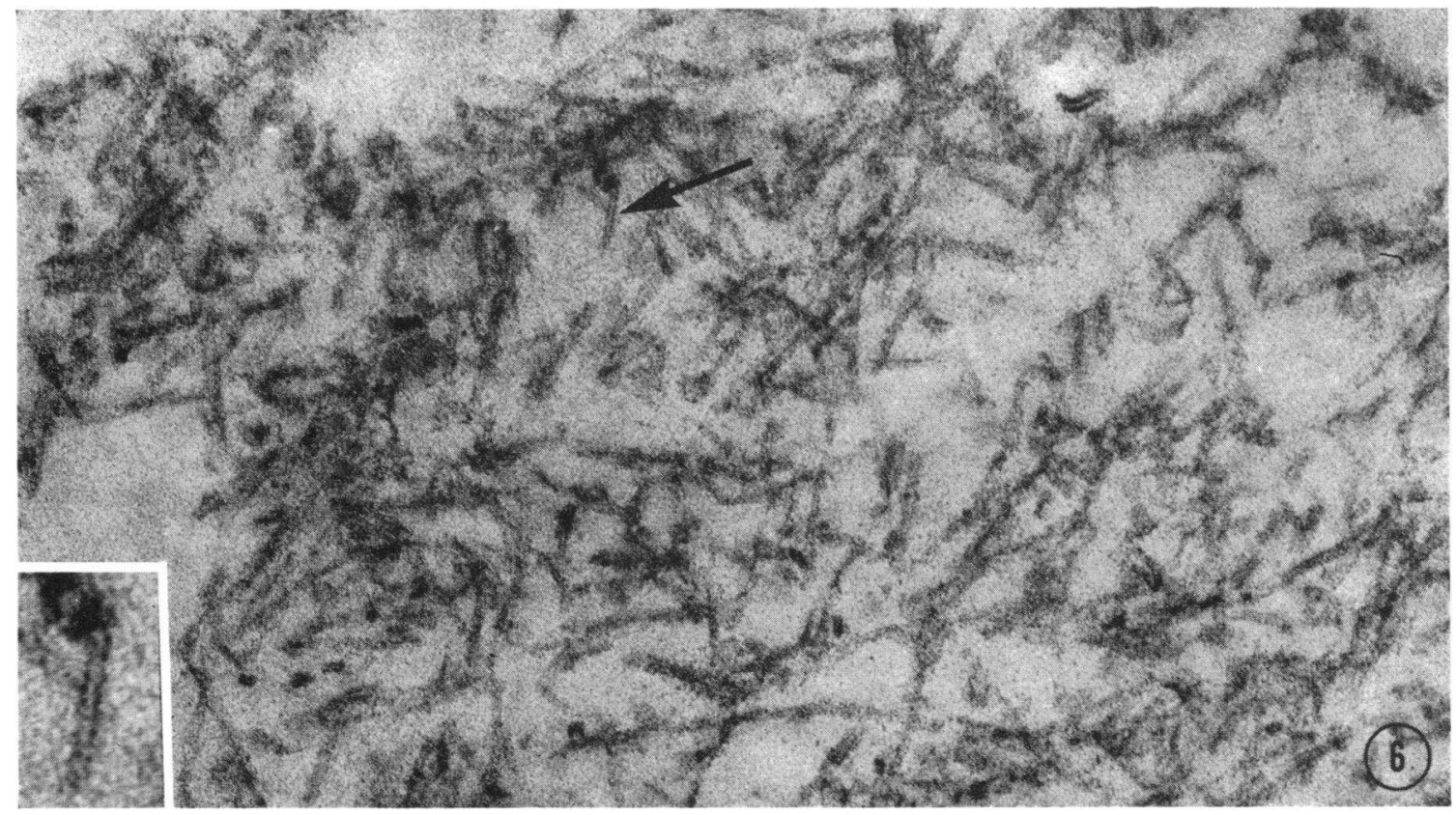

FIGURE 6 Appearance of fibrils in Epon-embedded sectioned amyloid. Fixation: glutaraldehyde and osmium tetroxide. Stain: uranyl acetate and lead hydroxide. Arrow points at a fibril which is seen at higher magnification in inset. Here the fibril can be seen to consist of two filaments with a beaded structure. $\times 120,000$. Inset $\times 330,000$.

rapidly sedimenting material probably represents a dimer of the original protein. In one instance only the $75 \mathrm{~S}$ peak was seen. After 5 wk an additional faster peak that had a sedimentation coefficient of about $100 \mathrm{~S}$ appeared, while the slow original $50 \mathrm{~S}$ peak had disappeared. When this material was centrifuged into a pellet, resuspended in distilled water, and subjected to homogenization in the Virtis-45 high speed homogenizer for 5 min, it again became transparent and sedimented as a single peak with a sedimentation coefficient of 45-50S.

Ultrastructure of fibrils. In thin positively stained sections (Fig. 6), amyloid isolated by the method described in this communication showed the fibrillar structure found in electron micrographs of sectioned amyloid-laden tissues by other investigators (11-18). The fibrils ranged from 80 to $200 \mathrm{~A}$ in width, the majority measuring roughly $100 \mathrm{~A}$. They crisscrossed into and out of the plane of section, making it difficult to determine their length. One of the longest fibrils seen in one plane measured $0.5 \mu$. In the salt-precipitated specimen, a large percentage of the fibrils consisted of two longitudinal subunits that were equal in width and separated by a space of $\pm 25 \mathrm{~A}$.
These two subunits appeared to remain parallel throughout their course (Figs. 6 and 7). However, when fibrils consisted of more than two longitudinal subunits, they pursued a parallel course only for a short distance, after which they twisted, crossed, or diverged. Scattered among the fibrils were irregularly shaped dots (Fig. 6) which probably represented tangential and cross sections of the fibrils. Their shape would presumably depend on the number of longitudinal subunits and the angle of the plane of section to the long axis of the fibril. Occasional cross sections showed a radiolucent core. The only differences noted between "soluble" and salt-precipitated amyloid in embedded and sectioned specimens were that in "soluble" amyloid the number of longitudinal subunits was smaller, the fibrils were generally shorter, and single units measuring only $\pm 40 \mathrm{~A}$ in diameter were often observed. As others have reported $(5,17,18)$, such single units appeared to have a beaded or helical structure.

The ultrastructure of the negatively stained preparations closely resembled that recently reported by Shirahama and Cohen (18) (Figs. 7-9). As these authors noted, the terminology adopted to describe amyloid fibrils in tissue sec- 


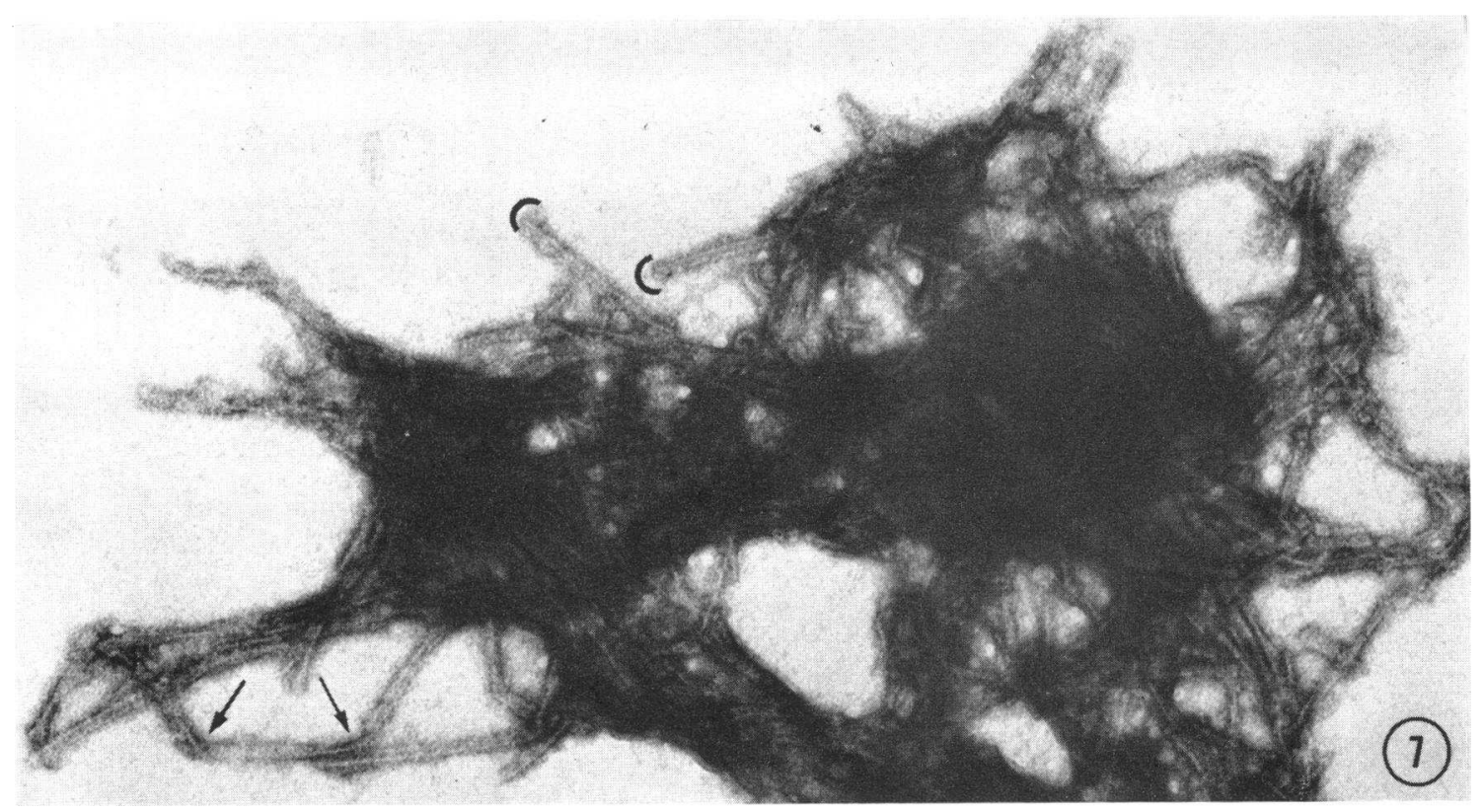

Figure 7 A clump of precipitated amyloid fibrils negatively stained with $1 \%$ phosphotungstate pH 5.5 . At the periphery of the clump, filaments run in pairs and end together (see half-circles). Arrows at bottom point to two twists in same pair of filaments. $\times 120,000$.

tions is difficult to apply to isolated negatively stained amyloid because of the greater resolution obtained in the latter specimens. Therefore, in describing the negatively stained material, we will avoid use of specific nomenclature as much as possible. However. in order to forestall confusion, we will call the unit structure most commonly seen at moderate magnifications amyloid filament, as Shirahama and Cohen have done (18). In all the preparations examined, filaments measured 40-75 $\mathrm{A}$ in diameter and ranged from several millimicrons in length to the smallest resolvable fragments. They clearly had a beaded or helical substructure which will not be described in detail here. The salt-precipitated amyloid showed thick bundles of filaments (sometimes as many as 30 could be counted within one bundle) as well as large clumps of intertwining filaments (Fig. 7). Strikingly, at the periphery of such clumps, the structures were commonly seen in pairs. In that case, they were separated by a dense area, presumably a space which varied from 30 to $60 \mathrm{~A}$ in different pairs, but which seemed to be uniform throughout the course of the same pair. Pairs of filaments remained parallel even when twisting occurred (Figs. 7 and 8), and they usually termi-

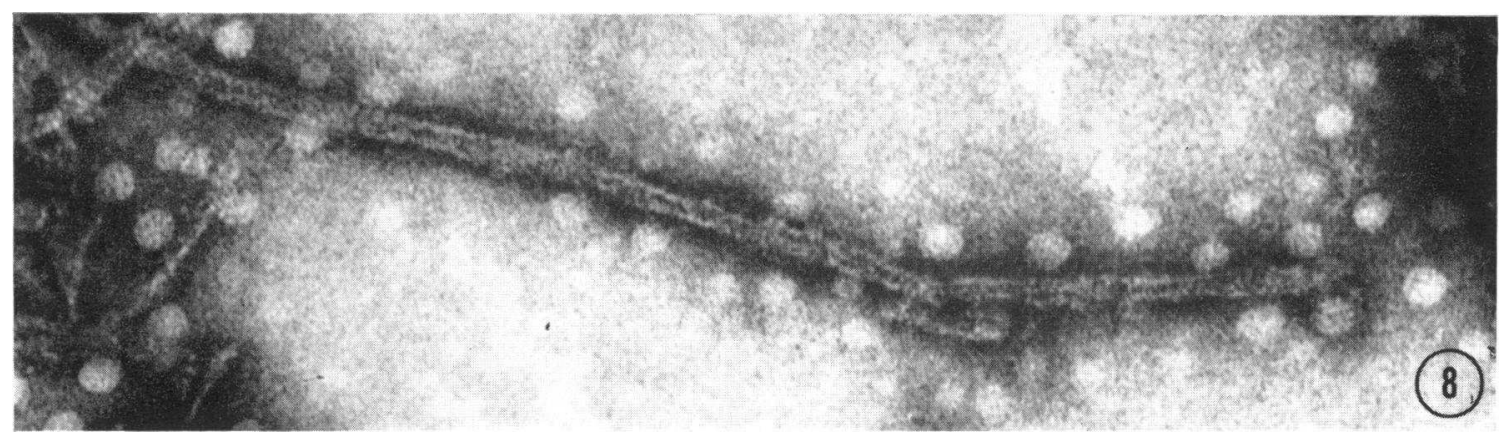

FIGURE 8 Salt-precipitated amyloid shows paired filaments negatively stained with $2 \%$ PTA. Note beaded structure and apparent break. $\times 200,000$. 


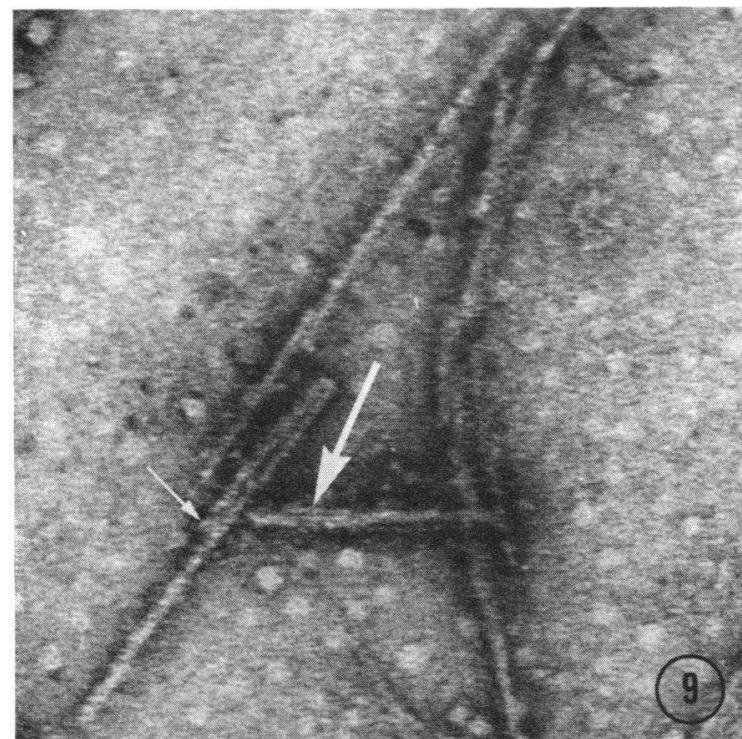

FIGURE 9 Negatively stained amyloid obtained from "soluble" preparation demonstrates that the bond between pairs of filaments is not firm. Small arrow points to an incomplete pair. Large arrow indicates smaller subunit which may represent the protofibril described by Shirahama and Cohen (18). White round objects are believed to be artifact of the preparation. $\times 200,000$.

nated together as if they had been formed or broken simultaneously. Binding of these lateral aggregates did not seem to be very firm, however, since incomplete pairs (Fig. 8) or splitting of a pair was sometimes seen. In addition to the filaments, smaller longitudinal subunits which measured only $20-25 \mathrm{~A}$ in width were seen singly or alongside the larger units (Fig. 8). A discussion of the relationship of these smaller structures to the filaments is beyond the scope of this paper, especially since a hypothetical interpretation of similar observations has been recently published (18).

Soluble amyloid, which had been allowed to dry on grids before the application of the contrasting agent, generally showed smaller clumps and thinner bundles of filaments. Moreover, single filaments and the small longitudinal units were more commonly encountered than in the salt-precipitated specimens.

\section{DISCUSSION}

The present study presents clear evidence that a protein having the known properties of amyloid has been obtained in a water-soluble form from the spleen of a patient with primary amyloidosis. Since the material recovered included almost all of the Congo red-binding substances present in the spleen, it seems likely that this represents a major fraction of the amyloid material. However, the possibility does remain that additional constituents of amyloid with different solubility properties may have remained in the insoluble residue. Furthermore, although amyloid from patients with primary, secondary, genetically determined amyloid and experimental amyloid from different species appear to have many common properties $(6,11-13)$, they may not be identical.

The unusual ability of amyloid to precipitate at low salt concentration, while many contaminating tissue constituents are soluble, was extremely useful in its purification. To extract this material, it was necessary first to homogenize the tissue and then to wash out the electrolytes present in the suspension. It would appear that once the fibrils are broken up, the electrolytes are responsible for the precipitation of the fibrils. A suspension of pure amyloid in saline or buffer will not dissolve to give a clear solution even on prolonged dialysis against distilled water. Only by repeated homogenization with distilled water, after removal of all salts, can a clear aqueous solution be obtained. The reason why solubility in water cannot be achieved by extensive and prolonged dialysis against water remains to be explained.

The method used here yields a product whose electronmicroscope appearance and chemical composition do not differ significantly from that prepared by Shirahama and Cohen's method $(6,15)$. An additional observation which proved of value in following the process of purification of the amyloid was the stoichiometric interaction with Congo red. Several preparations which appeared pure on ultracentrifugal analysis bound $0.32 \mathrm{mg}$ of dye per $1 \mathrm{mg}$ of amyloid.

Electronmicroscope studies of the fibrils under a variety of conditions in general confirmed the findings of Shirahama and Cohen (18). Individual filaments had a diameter of 40-75 $\mathrm{A}$ and ranged from a few angstroms to many angstroms in length. They were seen as single filaments, pairs. or large intertwining bundles containing as many as 30 or more filaments.

Although a precise relation of the material in solution and the fibrils has not been determined, 
it seems likely that the molecules in solution with sedimentation coefficient of 45-50S in water are much smaller than the fibrils seen in the electron microscope. It seems possible that the fibrils may represent polymers of these soluble molecules or, alternatively, a different physical state of the soluble amyloid. The fact that these molecules are highly reactive and tend to polymerize readily is indicated by the fact that the sedimentation coefficients rose from $50 \mathrm{~S}$ to $100 \mathrm{~S}$ with age, and that the solution became more and more opalescent on standing. It is not known whether amyloid reacts also with other proteins. If this were the case, this reactivity, taken together with its insolubility in salt, may be responsible for the deposition of amyloid in a variety of tissues.

A number of questions remain to be answered before the nature of amyloid can be definitively determined and its pathogenesis elucidated. Among these are the identity or nonidentity of amyloid in different disease states, its homogeneity or heterogeneity in any one disease, the nature of the binding of this highly reactive molecule to tissue constituents, and the factors that determine its sites of deposition. The similarity of electron micrographs of amyloid from a variety of tissues and different disease states (11-15) as well as the isolation of soluble amyloid with a sedimentation coefficient of about $45 \mathrm{~S}$ from a patient with familial Mediterranean fever (36) suggests that there may be many similarities in the structure of different preparations of amyloid. Additional studies of its primary, secondary, and tertiary structures and a more sophisticated search for serum proteins, such a $\gamma$-globulin and its fragments, in the purified preparations will shed much light on its precise nature. The availability of a pure, water-soluble preparation will help to provide answers to many of these questions in the near future.

\section{ACKNOWLEDGMENTS}

These studies were supported by U. S. Public Health Service grants AM 02594. AM 01431, AM 05064, and AM 00028. Dr. Pras is a U. S. Public Health Service Trainee in Rheumatology (Fulbright Fellow). Dr. Schubert is a recipient of U. S. Public Health Service Career Award AM 18434. Dr. Zucker-Franklin is a recipient of U. S. Public Health Service Career Development Award AI 9572. Dr. Rimon is a U. S. Public Health Service Research Fellow (TW 1065). Dr. Franklin is a N. Y. C. Health Research Council Career Scientist (I 274).

\section{REFERENCES}

1. Heller, H., J. Gafni, and E. Sohar. 1966. The inherited systemic amyloidoses. In The Metabolic Basis of Inherited Diseases. J. B. Stanbury, J. B. Wyngaarden, and D. S. Fredrickson, editors. McGrawHill, New York. 2nd edition. 995.

2. Cohen, A. S. 1965. The constitution and genesis of amyloid. In The International Review of Experimental Pathology. G. W. Richter and M. A. Epstein, editors. Academic Press, Inc., New York. 4: 159.

3. Newcombe, D. S., and A. S. Cohen. 1965. Solubility characteristics of isolated amyloid fibrils. Biochim. Biophys. Acta. 104: 480.

4. Benditt, E. P., D. Lagunoff, N. Eriksen, and O. A. Iseri. 1962. Amyloid: Extraction and preliminary characterization of some proteins. Arch. Pathol. 75: 323.

5. Benditt, E. P., and N. Eriksen. 1966. Amyloid III. A protein related to the subunit structure of human amyloid fibrils. Proc. Natl. Acad. Sci. U. S. 55: 308.

6. Cohen, A. S. 1966. Preliminary chemical analysis of partially purified amyloid fibrils. Laboratory Invest. $15: 66$.

7. Larsen, B. 1957. Presence of glycoproteins in secondary amyloid deposits related to serum glycoprotein. Acta Rheumatol. Scand. 3: 30.

8. Echmitz-Moorman, P. 1961. Biochemische und Histochemische Untersuchungen am Amyloid. Arch. Pathol. Anat. Physiol. 334: 95.

9. Letterer, E., W. Gerok, and G. Schneider. 1955. Vergleichende Untersuchungen über den Aminosäurenbestand von Serum-Eiweiss, Amyloid, Hyalin, Lebereiweiss und Kollagen. Arch. Pathol. Anat. Phy'siol. 327: 327 .

10. Pernis, B., G. Schneider, and C. Wunderly. 1953. Quantitative aminosäuerenanalyse von Amyloidsubstanz, elektrophoretischen Serum-Eiweissfraktionen und Bindegewebeprotein. Aerztl. Forsch. 7: 454.

11. Cohen, A. S., and E. Calkins. 1959. Electron microscopic observations on a fibrous component in amyloid of diverse origins. Nature. 183: 1202.

12. Caesar, R. 1960. Die Feinstruktur von Milz und Leber bei experimenteller Amyloidose. Z. Zellforsch. Microskop. Anat. Abt. Histochem. 52: 653.

13. Cohen, A. S., A. Frensdorff, S. Lamprecht, and E. Calkins. 1962. A study of the fine structure of the amyloid associated with Familial Mediterranean Fever. Am. J. Pathol. 41: 567.

14. Heefner, W. A., and G. D. Sorenson. 1962. Experimental amyloidosis. I. Light and electron microscopic observations of spleen and lymph nodes. Lab. Invest. 11: 585 .

15. Spiro, D. 1959. The structural basis of proteinuria in man. Electron microscopic study of renal biopsy specimens from patients with lipid nephrosis, amyloidosis, and subacute and chronic glomerulonephritis. Am. J. Pathol. 35 : 47. 
16. Gueft, B., and J. J. Ghidoni. 1963. The site of formation and ultrastructure of amyloid. Am. J. Pathol. 43: 837.

17. Bladen, H. A., M. U. Nylen, and G. G. Glenner. 1966. The ultrastructure of human amyloid as revealed by the negative staining technique. J. Ultrastruct. Res. $14: 449$.

18. Shirahama, T., and A. S. Cohen. 1967. High resolution electron microscopic analysis of the amyloid fibril. J. Cell. Biol. 33: 679.

19. Missmahl, H. P., and M. Hartwig. 1953. Polarizationoptische Untersuchungen an der Amyloidsubstanz. Arch. Pathol. Anat. Physiol. 324: 480.

20. Cohen, A. S.', and E. Calkins. 1964. The isolation of amyloid fibrils and a study of the effect of collagenase and hyaluronidase. J. Cell. Biol. 21: 481.

21. Trautman, R. 1956. Operating and comparing procedures facilitating Schlieren pattern analysis in analytical ultracentrifugation. J. Phys. Chem. 60: 1211.

22. Alberty, R. A. 1948. An introduction to electrophoresis. I. Methods and calculations. J. Chem. Educ. 25: 426; An introduction to electrophoresis. II. Analysis and theory. J. Chem. Educ. 25: 619.

23. Spackman, D. H. 1963. Accelerated system for the automatic analysis of amino acids. Federation Proc. 22: 244. (Abstr.)

24. Woessner, J. F., Jr. 1961. The determination of hydroxyproline in tissue and protein samples containing small proportions of this amino acid. Arch. Biochem. 93: 440 .

25. Yemm, E. W., and A. J. Willis. 1954. The estimation of carbohydrates in plant extracts by anthrone. Biochem J. $57: 508$.
26. Elson, L. A., and W. T. J. Morgan. 1933. A colorimetric method for determination of glucosamine and chondrosamine. Biochem. J. 27: 1824.

27. Dische, Z. 1947. A new specific color reaction of hexuronic acids. J. Biol. Chem. 167: 189.

28. Warren, L. 1959. The thiobarbituric acid assay of sialic acids. J. Biol. Chem. 234: 1971.

29. Brenner, S., and R. W. Horne. 1959. A negative staining method for high resolution electron microscopy of viruses. Biochim. Biophys. Acta. 34: 103.

30. Sabatini, D. D., K. Bensch, and R. S. Barnett. 1963. Cytochemistry and electron microscopy. The preservation of cellular ultrastructure and enzymatic activity by aldehyde fixation. J. Cell. Biol. 17: 19.

31. Luft, J. H. 1961. Improvements in epoxy resin embedding methods. J. Biophys. Biochem. Cytol. 9: 409.

32. Watson, M. L. 1958. Staining of tissue sections for electron microscopy with heavy metals. J. Biophys. Biochem. Cytol. 4: 475.

33. Millonig, G. 1961. A modified procedure for lead staining of thin sections. J. Biophys. Biochem. Cytol. 11: 736.

34. Mellema, J. E., E. F. J. Van Bruggen, and $M$. Gruber. 1967. Uranyl oxalate as a negative stain for electron microscopy of proteins. Biochim. Biophys. Acta. 140: 180.

35. Pirani, C. L., A. Bestetti, H. R. Catchpole, and M. Meskauskas. 1964. Isolation and characterization of amyloid. Arthritis Rheumat. 7: 338. (Abstr.)

36. Ashkenazi, I., H. Hershko, J. Gafni, E. Sohar, and H. Heller. 1967. The isolation of highly purified amyloid. Israel J. Med. Sci. 3: 569. 